\title{
Studi Kepuasan Pelanggan Terhadap Pelayanan Air Bersih Perumda Tirta Muaro Unit Teluk Singkawang
}

\author{
Siti Umi Kalsum, Asih Suzana, Amira Qotrunada Harahap* \\ Program Studi Teknik Lingkungan, Fakultas Teknik, Universitas Batanghari \\ Jalan Slamet Riyadi, Kota Jambi \\ *e-mail: amiraqh94@gmail.com
}

\begin{abstract}
PERUMDA Tirta Muaro Unit Teluk Singkawang in the dimension of assurance is still not good. As evidenced by the low scope of service in this unit. Marked by the number of customers in 2020 as many as 2035 people. While the population of Sumay Subdistrict in 2020 as many as 21,398 people (Tebo Regency in Numbers, 2021). This means that the service coverage is $9.5 \%$. This has not met the government's target of drinking water services of $75 \%$ for rural areas (Permen PU No. 13, 2013).This type of research includes explorative descriptive research using qualitative statistical research techniques. This research method uses survey method with customer population of PERUMDA Tirta Muaro Unit Teluk Singkawang. Sampling techniques using slovin formula. The analysis technique uses multiple linear regression analysis, with $F$ test and $t$ test using SPSS software. The results of the study that the level of customer satisfaction based on respondents' responses to 5 (five) dimensions of service quality received a score of 3.54 in the category of satisfied.
\end{abstract}

Keywords: Costumer Satisfication; Tangible; Realibility; Responsiveness; Assurance; Empathy.

\section{Pendahuluan}

Air merupakan salah satu unsur penting bagi makhluk hidup di bumi ini termasuk manusia. Tanpa air manusia akan sulit untuk melangsungkan hidupnya, maka pengelolaannya harus diatur dengan bijak agar dapat dimanfaatkan secara efektif dan efisien sehingga dapat digunakan berkelanjutan. Pelayanan air bersih menurut Gronroos dalam Winarsih (2005) adalah suatu aktivitas atau serangkaian aktivitas yang bersifat tidak kasat mata (tidak dapat diraba) yang terjadi sebagai akibat adanya interaksi antara konsumen/pelanggan dengan karyawan atau hal-hal lain yang disediakan oleh perusahaan pemberi pelayanan air bersih (PDAM) yang dimaksudkan untuk memecahkan permasalahan konsumen/pelangggan.

Kabupaten Tebo telah memiliki perusahaan umum daerah air minum yaitu PERUMDA Tirta Muaro untuk memenuhi kebutuhan air bersih masyarakat Kabupaten Tebo. PERUMDA Tirta Muaro saat ini terdiri dari 14 unit pelayanan yaitu antara lain yaitu Muaro Tebo, Unit Sungai Bengkal, Unit Koto Jayo, Unit Pulau Temiang, Unit Betung Bedarah Barat, Unit Muara Tabir, Unit Teluk Kuali, Unit Teluk Singkawang, Unit Cermin Alam, Unit Rimbo Ilir, Unit Wirotho Agung, Unit Teluk Rendah, Unit Rimbo Ulu dan Unit Rimbo Bujang. PERUMDA Tirta Muaro Unit Teluk Singkawang merupakan unit yang melayani kebutuhan air bersih untuk wilayah Kecamatan Sumay. Unit ini melayani 3 (tiga) desa dari 12 (dua belas) desa yang terdapat di Kecamatan Sumay.

PERUMDA Tirta Muaro Unit Teluk Singkawang secara dimensi jaminan (assurance) masih belum baik. Terbukti dengan masih rendahnya cakupan pelayanan pada unit ini. Ditandai dengan jumlah pelanggan pada tahun 2020 sebanyak 2035 jiwa. Sedangkan jumlah penduduk Kecamatan Sumay tahun 2020 sebanyak 21.398 jiwa (Kabupaten Tebo dalam Angka, 2021). Artinya cakupan pelayanannya sebesar 9,5\%. Hal ini belum memenuhi target pemerintah terhadap pelayanan air minum yaitu sebesar $75 \%$ untuk kawasan perdesaan (Permen PU Nomor 13, 2013). Secara kehandalan (reliability) PERUMDA Tirta Muaro Unit Teluk Singkawang masih belum baik. Terbukti dengan jam operasional distribusi air saat ini masih sekitar 10 jam/hari (PERUMDA Tirta Muaro
Unit Teluk Singkawang, 2020). Artinya belum sesuai dengan standar peraturan pendistribusian air yang tertuang pada Peraturan Pemerintah No. 122 Tahun 2015 tentang Sistem Penyediaan Air Minum yaitu wajib memberikan jaminan pengaliran selama 24 jam/hari. Kualitas pelayanan PDAM sebagaimana menurut Batubara, et al., (2014) meliputi dimensi tangible, reliability, assurance, responsiveness dan emphaty.

Tujuan penelitian ini adalah untuk mengetahui tingkat kepuasan pelanggan terhadap pelayanan air bersih PERUMDA Tirta Muaro Unit Teluk Singkawang berdasarkan 5 (lima) dimensi kualitas pelayanan.

\section{Metode Penelitian}

\subsection{Jenis Penelitian}

Jenis penelitian ini termasuk penelitian deskriptif eksploratif dengan menggunakan teknik penelitian statistik kualitatif.

\subsection{Lokasi dan Waktu Penelitian}

Penelitian ini dilakukan di PERUMDA Tirta Muaro Unit Teluk Singkawang Kecamatan Sumay Kabupaten Tebo. Wilayah yang dijadikan tempat penelitian adalah Desa Teluk Singkawang, Teriti dan Desa Lembak Bungur Kecamatan Sumay Kabupaten Tebo Provinsi Jambi. Penelitian dimulai pada bulan September hingga bulan Desember tahun 2020.

\subsection{Teknik Pengumpulan Data \\ 1. Data Primer}

Data primer yaitu data yang didapat oleh peneliti untuk maksud khusus menyelesaikan permasalahan yang sedang ditanganinya. Data dikumpulkan sendiri oleh peneliti langsung dari sumber pertama atau tempat objek penelitian dilakukan. Teknik yang digunakan dalam pengumpulan data primer antara lain:

1. Wawancara

2. Angket

Populasi dan Teknik Sampling 
Jumlah populasi dalam penelitian ini adalah jumlah pelanggan PERUMDA Tirta Muaro Unit Teluk Singkawan, yaitu sebanyak 407 pelanggan. Teknik sampling merupakan cara menentukan sampel yang jumlahnya sesuai dengan ukuran sampel yang akan dijadikan sumber data sebenarnya, dengan memperhatikan sifat-sifat dan penyebaran populasi agar diperoleh sampel yang representatif. Teknik pengambilan sampel yang digunakan dalam penelitian ini yaitu dengan rumus Slovin:

$$
\mathrm{n}=\frac{N}{1+N e^{2}}
$$

Dalam rumus Slovin ada ketentuan sebagai berikut:

Nilai e $=0,1(10 \%)$ untuk populasi dalam jumlah besar

Nilai e $=0,2(20 \%)$ untuk populasi dalam jumlah kecil

Dengan rumus tersebut, didapat jumlah sampel:

$\mathrm{N}=\frac{N}{1+N e 2}$

$\mathrm{N}=\frac{407}{1+407(0,1)^{2}}=80$ responden.

\section{Data Sekunder}

Data sekunder merupakan data yang diperoleh melalui buku-buku, jurnal, maupun artikel yang berkaitan dengan penelitian. Data sekunder yang dibutuhkan dalam penelitian ini yaitu peta wilayah, peta pelayanan, data jumlah pelanggan, data jumlah penduduk Kecamatan Sumay. Teknik pengumpulan data sekunder sebagai berikut:

\section{Dokumentasi}

2. Studi Literatur

\subsection{Variabel Peneltian}

Dimensi kualitas pelayanan menurut Rangkuti (2006 : 29-30) terdapat lima dimensi untuk mengukur kualitas pelayanan $(\mathrm{X})$, yaitu :

1. Bukti lansung (tangibles) (X1)

Kemampuan suatu perusahaan dalam menunjukkan eksistensinya kepada pihak eksternal yang meliputi fasilitas fisik, perlengkapan, pegawai, dan sarana komunikasi.

2. Keandalan (reliability) (X2)

Kemampuan memberikan pelayanan sesuai dengan yang dijanjikan dengan segera, akurat, tepat, dan memuaskan.

3. Ketanggapan (responsiveness) (X3) Keinginan para staf dan karyawan untuk membantu para pelanggan dan memberikan pelayanan dengan tanggap.

4. Jaminan (assurance) (X4)

Mencakup pengetahuan, kemampuan, kesopanan, dan sifat dapat dipercaya yang dimiliki paraa staf; bebas dari bahaya, resiko atau keragu - raguan.

5. Empati (empathy) (X5)

Kemudahan daalam melakukan hubungan, komunikasi yang baik, perhatian pribadi, dan memahami kebutuhan para pelanggan.

Variabel diatas merupakan Dependen Variabel yang akan dilihat keterkaitannya dengan Independen Variabel yang diwakili oleh Kepuasan Pelanggan (Y).

\subsection{Teknik Analisis}

Analisa data mengunakan pengujian statistik menggunakan program SPSS (Statistical Product And Service Solution). Kegiatan yang dilakukan dalam tahap ini ialah menganalisis data hasil survai berdasarkan perhitungan statistika dan membuat model berupa analisa klasifikasi silang (crosstab) dengan kriteria koefisien korelasi (r), nilai banding $F$, nilai banding $t$. Interpretasi yang dihasilkan merupakan suatu penarikan kesimpulan mengenai adanya keterkaitan antara 2 (dua) variabel.

\section{Analisis Tingkat Kepuasan Pelanggan}

Analisis untuk mengetahui tingkat kepuasan pelanggan terhadap pelayanan air bersih didasarkan atas sistem penilaian dari skala Likert. Pilihan jawaban dengan skor besar merupakan jawaban yang dianggap mempunyai tingkat kepuasan paling tingg. Nilai indikator kepuasan pelanggan dapat dilihat pada Tabel 1 .

Tabel 1. Nilai Indikator Tingkat Kepuasan Pelanggan

\begin{tabular}{cc}
\hline Nilai & Tingkat Kepuasan \\
\hline$>4-5$ & Sangat Puas \\
$>3-4$ & Puas \\
$>2-3$ & Cukup Puas \\
$>1-2$ & Tidak Puas \\
$<1$ & Sangat Tidak Puas \\
\hline
\end{tabular}

\section{Hasil dan Pembahasan}

\subsection{Identitas Responden}

a. Deskripsi Responden Berdasarkan Jenis Kelamin

Reponden yang diteliti dibedakan berdasarkan jenis kelamin. Hal ini dimaksudkan untuk mengetahui sejauh mana keterlibatan pelanggan baik laki-laki maupun perempuan dalam memanfaatkan jasa dari PERUMDA Tirta Muaro Unit Teluk Singkawang Kecamatan Sumay Kabupaten Tebo.

Tabel 2. Responden Berdasarkan Jenis Kelamin

\begin{tabular}{cccc}
\hline No. & $\begin{array}{c}\text { Jenis } \\
\text { Kelamin }\end{array}$ & $\begin{array}{c}\text { Jumlah } \\
\text { Pelanggan }\end{array}$ & Persentase \\
\hline 1. & Laki-laki & 24 & 30 \\
2. & Perempuan & 56 & 70 \\
\hline & Jumlah & 80 & 100 \\
\hline
\end{tabular}

b. Deskripsi Lama Menjadi Pelanggan

Responden yang diteliti dibedakan berdasarkan lamanya menjadi pelanggan. Hal ini dimaksudkan untuk mengetahui sejauh mana keterlibatan pelanggan berdasarkan lamanya menjadi pelanggan PERUMDA Tirta Muaro Unit Teluk Singkawang Kecamatan Sumay Kabupaten Tebo.

Tabel 3. Responden Berdasarkan Lama Menjadi Pelanggan

\begin{tabular}{cccc}
\hline No. & $\begin{array}{c}\text { Lama } \\
\text { Menjadi } \\
\text { Pelanggan }\end{array}$ & $\begin{array}{c}\text { Jumlah } \\
\text { Pelanggan }\end{array}$ & Persentase \\
\hline 1 & $>1$ Tahun & 2 & 2,50 \\
2 & 1-3 Tahun & 18 & 22,50 \\
3 & 3-5 Tahun & 25 & 31,25 \\
4 & $>$ 5 Tahun & 35 & 43,75 \\
\hline & Jumlah & 80 & 100,00 \\
\hline
\end{tabular}

c. Deskripsi Kepemilikan Rumah

Responden yang diteliti dibedakan berdasarkan kepemilikan rumah. Hal ini dimaksudkan untuk mengetahui sejauh mana keterlibatan pelanggan berdasarkan kepemilikan rumah menjadi pelanggan PERUMDA Tirta Muaro Unit Teluk Singkawang Kecamatan Sumay Kabupaten Tebo. 
Tabel 4. Responden Berdasarkan Kepemilikan Rumah

\begin{tabular}{clcc}
\hline No. & $\begin{array}{c}\text { Kepemilikan } \\
\text { Rumah }\end{array}$ & $\begin{array}{c}\text { Jumlah } \\
\text { Orang }\end{array}$ & Persentase \\
\hline 1 & Milik Sendiri & 75 & 93,75 \\
2 & Sewa Kontrak & 2 & 2,50 \\
3 & Rumah Dinas & 3 & 3,75 \\
\hline & Jumlah & 80 & 100,00 \\
\hline
\end{tabular}

\section{d. Deskripsi Pekerjaan}

Responden yang diteliti dibedakan berdasarkan pekerjaan. Hal ini dimaksudkan untuk mengetahui sejauh mana keterlibatan pelanggan berdasarkan jenis pekerjaan yang menjadi pelanggan PERUMDA Tirta Muaro Unit Teluk Singkawang Kecamatan Sumay Kabupaten Tebo.

Tabel 5. Responden Berdasarkan Jenis Pekerjaan

\begin{tabular}{clcc}
\hline No. & \multicolumn{1}{c}{ Pekerjaan } & $\begin{array}{c}\text { Jumlah } \\
\text { Pelanggan }\end{array}$ & Persentase \\
\hline 1 & PNS & 2 & 2,50 \\
2 & Karyawan Swasta & 19 & 23,75 \\
3 & Petani & 38 & 47,50 \\
4 & Ibu Rumah Tangga & 21 & 26,25 \\
\hline \multicolumn{2}{r}{ Jumlah } & 80 & 100,00 \\
\hline
\end{tabular}

e. Deskripsi Rata-Rata Besaran Pembayaran Tagihan

Responden yang diteliti dibedakan berdasarkan ratarata besaran pembayaran tagihan setiap bulannya. Hal ini dimaksudkan untuk mengetahui sejauh mana keterlibatan pelanggan berdasarkan rata-rata besaran pembayaran tagihan setiap bulannya yang menjadi pelanggan PERUMDA Tirta Muaro Unit Teluk Singkawang Kecamatan Sumay Kabupaten Tebo.

Tabel 5. Responden Berdasarkan Rata-Rata Pembayaran Tagihan

\begin{tabular}{|c|c|c|c|}
\hline No. & $\begin{array}{c}\text { Besaran Tagihan Per } \\
\text { Bulan }\end{array}$ & $\begin{array}{c}\text { Jumlah } \\
\text { Pelanggan }\end{array}$ & Persentase \\
\hline 1. & $<$ Rp. 50.000 & 12 & 15,00 \\
\hline 2. & Rp. 50.000 - Rp. 75.000 & 22 & 27,50 \\
\hline 3. & Rp. 75.000 - Rp. 100.000 & 30 & 37,50 \\
\hline 4. & $>$ Rp. 100.000 & 16 & 20,00 \\
\hline & Jumlah & 80 & 100,00 \\
\hline
\end{tabular}

f. Deskripsi Rata-Rata Besaran Penghasilan

Responden yang diteliti dibedakan berdasarkan ratarata besara penghasilan per bulan. Hal ini dimaksudkan untuk mengetahui sejauh mana keterlibatan pelanggan berdasarkan rata-rata besaran penghasilan per bulan yang menjadi pelanggan PERUMDA Tirta Muaro Unit Teluk Singkawang Kecamatan Sumay Kabupaten Tebo.

Tabel 6. Responden Berdasarkan Rata-Rata Penghasilan Per Bulan

\begin{tabular}{clcc}
\hline No. & Besaran Penghasilan & $\begin{array}{c}\text { Jumlah } \\
\text { Pelanggan }\end{array}$ & Persentase \\
\hline 1 & Rp. 500.000 - Rp. 1.000.000 & 12 & 15,00 \\
2 & Rp. 1.000.000 - Rp. 2.000.000 & 34 & 42,50 \\
3 & Rp. 2.000.000 - Rp. 3.000.000 & 29 & 36,25 \\
4 & > Rp. 3.000.000 & 5 & 6,25 \\
\hline \multicolumn{2}{c}{ Jumlah } & 80 & 100,00 \\
\hline
\end{tabular}

\subsection{Deskripsi Kualitas Pelayanan}

Kualitas pelayanan adalah bentuk penilaian konsumen pada tingkat pelayanan yang diterima (perceived service) dengan tingkat pelayanan yang diharapkan (expected Service). Kualitas layanan tergantung pada kemampuan perusahaan dalam hal ini PERUMDA dalam memberi layanan air bersih sesuai harapan pelanggan secara konsisten. Adapun variabel bebas $(\mathrm{X})$ yaitu tentang kualitas pelayanan yang dibahan lebih lanjut dalam 5 dimensi yaitu tangibles, responsiveness, reliability, assurance dan emphaty.

a. Tanggapan Responden Terhadap Dimensi Tangibles

Tangibles merupakan kemampuan dari perusahaan yaitu PERUMDA Tirta Muaro Unit Teluk Singkawang Kecamatan Sumay Kabupaten Tebo dalam menunjukkan keberadaannya terhadap pihak eksternal yaitu pelanggan. Tangibles akan diuji melalui indikator kemampuan dan penampilan produk.

Berdasarkan hasil penyebaran kuisioner dapat diketahui distribusi jawaban responden untuk dimensi Tangibles, sebagai berikut.

Tabel 7. Tanggapan Responden Terhadap Dimensi Tangibles

\begin{tabular}{|c|c|c|c|c|c|c|}
\hline \multirow{2}{*}{ Atribut } & \multicolumn{5}{|c|}{ Jumlah Responden } & \multirow{2}{*}{ Mean } \\
\hline & SK & $\mathrm{K}$ & SK & TK & SSTK & \\
\hline Tingkat kekeruhan air (X1.1) & 1 & 11 & 45 & 23 & 0 & \\
\hline$\%$ & $\begin{array}{l}1,3 \\
\text { SB }\end{array}$ & $\begin{array}{l}14 \\
B\end{array}$ & $\begin{array}{l}56,3 \\
\text { SB }\end{array}$ & $\begin{array}{c}28,8 \\
\text { TB }\end{array}$ & $\begin{array}{c}0 \\
\text { SST }\end{array}$ & 4,11 \\
\hline Air tidak berbau (X1.2) & 1 & 17 & 48 & 14 & 0 & \\
\hline$\%$ & $\begin{array}{c}1,3 \\
\text { STM }\end{array}$ & $\begin{array}{l}21 \\
\mathrm{TM}\end{array}$ & $\begin{array}{l}60 \\
\mathrm{CM}\end{array}$ & $\begin{array}{c}16,5 \\
M\end{array}$ & $\begin{array}{c}0 \\
\text { SM }\end{array}$ & 3,93 \\
\hline $\begin{array}{l}\text { Air dapat memenuhi } \\
\text { kebutuhan sehari-hari (X1.3) }\end{array}$ & 1 & 42 & 34 & 3 & 0 & 2,49 \\
\hline Total R & $\begin{array}{l}1,3 \\
\text { a-Rata }\end{array}$ & $\begin{array}{c}53 \\
\text { Mean }\end{array}$ & 42,5 & 3,8 & & 3,51 \\
\hline
\end{tabular}

Skor tertinggi mengenai dimensi tangibles adalah sebesar 4,11 yaitu tingkat kekeruhan air yang dinilai oleh responden sedikit keruh. Secara keseluruhan untuk dimensi tangibles memiliki total nilai rata-rata (mean) sebesar 3,51 dibawah 4, artinya responden menilai dimensi tangibles yang ada pada PERUMDA Tirta Muaro Unit Teluk Singkawang belum memenuhi harapan penggunanya atau pelanggan.

1) Dari sisi tingkat kekeruhan air yang diproduksi oleh PERUMDA Tirta Muaro Unit Teluk Singkawang pada umumnya masih sedikit keruh;

2) Air yang didistribusikan ke pelanggan sedikit berbau;

3) Air tidak dapat memenuhi kebutuhan sehari-hari.

\section{b. Tanggapan Responden Terhadap Dimensi Reliability}

Reliability merupakan kemampuan PERUMDA untuk memberikan pelayanan berdasarkan apa yang dijanjikan secara terpercaya dan akurat. Kinerja diuji lebih lanjut dengan keinginan pelanggan seperti kecepatan dalam pelayanan, sikat petugas dalam menghadapi keluhan, sikap dalam menanggapi pertanyaan konsumen.

Berdasarkan hasil penyebaran kusioner dapat diketahui distribusi jawaban responden untuk dimensi reliability sebagai berikut. 
Tabel 8. Tanggapan Responden Terhadap Dimensi Reliability

\begin{tabular}{|c|c|c|c|c|c|c|}
\hline \multirow{2}{*}{ Atribut } & \multicolumn{5}{|c|}{ Jumlah Responden } & \multirow{2}{*}{ Mean } \\
\hline & STS & TS & $\mathrm{CS}$ & $\mathrm{S}$ & SS & \\
\hline \multirow[t]{3}{*}{$\begin{array}{l}\text { Kemudahan akses } \\
\text { pembayaran tagihan } \\
\text { (X3.1) }\end{array}$} & 1 & 7 & 9 & 18 & 45 & \multirow[t]{2}{*}{4,24} \\
\hline & 1,3 & 8,8 & 11,3 & 22,5 & 56,3 & \\
\hline & STS & TS & $\mathrm{CS}$ & $\mathrm{S}$ & SS & \\
\hline $\begin{array}{l}\text { Kemudahan } \\
\text { menyampaikan keluhan } \\
\text { (X.3.2) }\end{array}$ & 1 & 4 & 12 & 62 & 1 & \multirow[t]{2}{*}{3,73} \\
\hline$\%$ & 1,3 & 5 & 15 & 77,5 & 1,3 & \\
\hline Total F & ata-Ra & (Mear & & & & 3,99 \\
\hline
\end{tabular}

Secara keseluruhan, untuk dimensi reliability memiliki total rata-rata (mean) sebesar 3,99 atau mendekati skor 4, artinya responden menilai reliability yang ada pada PERUMDA Tirta Muaro Unit Teluk Singkawang sudah sepenuhnya memenuhi harapan penggunanya atau pelanggan.

1) Petugas PERUMDA Tirta Muaro Unit Teluk Singkawang masih belum bertindak cepat dalam menangani keluhan pelanggan;

2) Petugas PERUMDA Tirta Muaro Unit Teluk Singkawang masih belum bertindak cepat dalam mengatasi kasus kebocoran pipa pada konsumen.

\section{c. Tanggapan Responden Terhadap Dimensi Responsiveness}

Responsiveness merupakan kemauan PERUMDA Tirta Muaro Unit Teluk Singkawang untuk membantu dan memberikan pelayanan yang cepat (responsive) dan tepat terhadap konsumen, cara menyampaikan informasi dengan jelas. Menghindari pelanggan sampai menunggu tanpa adanya suatu alasan yang jelas, sehingga mengakibatkan persepsi negatif dari kualitas pelayanan.

Berdasarkan hasil penyebaran kusioner dapat diketahui distribusi jawaban responden untuk dimensi responsive sebagai berikut.

Tabel 9. Tanggapan Responden Terhadap Dimensi Responsive

\begin{tabular}{|c|c|c|c|c|c|c|}
\hline \multirow{2}{*}{ Atribut } & \multicolumn{5}{|c|}{ Jumlah Responden } & \multirow{2}{*}{ Mean } \\
\hline & STS & TS & $\mathrm{CS}$ & $\mathrm{S}$ & ST & \\
\hline $\begin{array}{l}\text { Penanganan keluhan } \\
\text { pelanggan (X.2.1) }\end{array}$ & 2 & 32 & 8 & 37 & 1 & \multirow[t]{2}{*}{3,04} \\
\hline$\%$ & 2,5 & 40 & 10 & 46,3 & 2,3 & \\
\hline & STS & TS & $\mathrm{CS}$ & $\mathrm{S}$ & ST & \\
\hline $\begin{array}{l}\text { Kecepatan menangani } \\
\text { kebocoran (X.2.2) }\end{array}$ & 36 & 9 & 4 & 13 & 18 & \multirow[t]{2}{*}{2,60} \\
\hline 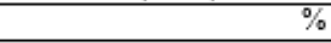 & 45 & 11 & 5 & 16,3 & 22,5 & \\
\hline
\end{tabular}

Secara keseluruhan, untuk dimensi responsive memiliki total rata-rata (mean) sebesar 2,82 atau masih dibawah 4, artinya responden menilai dimensi daya tanggap (responsive) yang ada pada PERUMDA Tirta Murao Unit Teluk Singkawang belum memenuhi harapan penggunanya atau pelanggan.

1) PERUMDA Tirta Muaro Unit Teluk Singkawang Kecamatan Sumay Kabupaten Tebo masih belum cepat dalam penanganan keluhan pelanggan;

2) PERUMDA Tirta Muaro Unit Teluk Singkawang Kecamatan Sumay Kabupaten Tebo masih belum memberikan tanggapan yang cepat terhadap kebocoran pipa pada konsumen.

\section{d. Tanggapan Responden Terhadap Dimensi Assurance}

Assurance merupakan kemampuan, pengetahuan dan kesopansantunan dari para pegawai PERUMDA Tirta Muaro Unit Teluk Singkawang Kecamatan Sumay Kabupaten Tebo untuk menumbuhkan kepercayaan terhadap para pelanggan. Beberapa komponen assurance seperti komunikasi (communication), kredibilitas (credibility), keamanan (security), kompetensi (competence) dan sopan santun (courtesy).

Berdasarkan hasil penyebaran kuisioner dapat diketahui distribusi jawaban responden untuk dimensi assurance, sebagai berikut.

Tabel 10. Tanggapan Responden Terhadap Dimensi Assurance

\begin{tabular}{|c|c|c|c|c|c|c|}
\hline \multirow{2}{*}{ Atribut } & \multicolumn{5}{|c|}{ Jumlah Responden } & \multirow{2}{*}{ Mean } \\
\hline & STS & TS & $\mathrm{CS}$ & $\mathrm{S}$ & ST & \\
\hline $\begin{array}{l}\text { Pelayanan sudah Baik } \\
\text { (X4.1) }\end{array}$ & 1 & 5 & 35 & 39 & 0 & \multirow[t]{2}{*}{4,39} \\
\hline \multirow[t]{2}{*}{$\%$} & 1,3 & 6,3 & 43,8 & 48,8 & 0 & \\
\hline & STS & TS & $\mathrm{CS}$ & $\mathrm{S}$ & ST & \\
\hline $\begin{array}{l}\text { Kualitas air sudah baik } \\
\text { (X.4.2) }\end{array}$ & 1 & 4 & 60 & 12 & 3 & \multirow[t]{2}{*}{3,15} \\
\hline$\%$ & 1,3 & 5 & 75 & 15 & 3,8 & \\
\hline \multicolumn{6}{|c|}{ Total Rata-Rata (Mean) } & 3,77 \\
\hline
\end{tabular}

Skor teringgi mengenai dimensi assurance adalah sebesar 4,39 yaitu pelayanan yang diberikan oleh PERUMDA Tirta Muaro Unit Teluk Singkawang Kecamatan Sumay Kabupaten Tebo kepada pelanggan. Secara keseluruhan untuk dimensi assurance memiliki total rata-rata (mean) sebesar 3,77 atau mendekati skor 4, artinya responden menilai dimensi assurance yang ada pada PERUMDA Tirta Muaro Unit Teluk Singkawang Kecamatan Sumay Kabupaten Tebo telah memenuhi harapan penggunanya atau pelanggan.

1) PERUMDA Tirta Muaro Unit Teluk Singkawang Kecamatan Sumay Kabupaten Tebo telah memberikan pelayanan yang baik kepada pelangggannya;

2) PERUMDA Tirta Muaro Unit Teluk Singkawang Kecamatan Sumay Kebupaten Tebo telah memberikan kualitas air yang baik kepada pelanggannya.

\section{e. Tanggapan Responden Terhadap Dimensi Empathy}

Empathy merupakan pemberian perhatian yang tulus dan bersifat individual atau pribadi yang diberikan terhadap pelanggan dengan upaya memahami setiap keinginan pelanggan.

Tabel 11. Tanggapan Responden Terhadap Dimensi Empathy

\begin{tabular}{|c|c|c|c|c|c|c|}
\hline \multirow{2}{*}{ Atribut } & \multicolumn{5}{|c|}{ Jumlah Responden } & \multirow{2}{*}{ Mean } \\
\hline & STS & TS & $\mathrm{CS}$ & $\mathbf{S}$ & ST & \\
\hline $\begin{array}{l}\text { Petugas bersikap sopan } \\
\text { menanggapi keluhan }\end{array}$ & 1 & 11 & 18 & 46 & 4 & \multirow[t]{2}{*}{3,51} \\
\hline$\%$ & 1,3 & 14 & 22,5 & 57,5 & 5 & \\
\hline & STS & TS & $\mathrm{CS}$ & $\mathrm{S}$ & ST & \\
\hline $\begin{array}{l}\text { Petugas bersikap sopan } \\
\text { dalam melayani konsumen }\end{array}$ & 1 & 2 & 44 & 7 & 26 & \multirow[t]{2}{*}{3,69} \\
\hline$\%$ & 1,3 & 2,5 & 55 & 8,8 & 32,5 & \\
\hline
\end{tabular}

PERUMDA Tirta Muaro Unit Teluk Singkawang diharapkan mempunyai pengetahuan dan pemahaman mengenai pelanggan, memiliki waktu operasi yang nyaman untuk pelanggan dan kebutuhan pelanggan secara spesifik. 
Berdasarkan hasil penyebaran kusioner dapat diketahui distribusi jawaban responden untuk dimensi empathy, sebagaimana ditampilkan pada tabel 11. Secara keseluruhan, untuk dimensi empathy memiliki total rata-rata (mean) sebesar 3,60 atau mendekati skor 4, artinya responden menilai dimensi empathy petugas PERUMDA Tirta Muaro Unit Teluk Singkawang Kecamatan Tebo telah memenuhi harapan penggunanya atau pelanggan.

1) Petugas PERUMDA Tirta Muaro Unit Teluk Singkawang bersikap sopan dan ramah dalam menangani keluhan/permasalahan pelanggan;

2) Petugas PERUMDA Tirta Muaro Unit Teluk Singkawang Kecamatan Sumay Kabupaten Tebo bersikap sopan dan ramah dalam memberikan pelayakan kepada pelanggan.

Berdasarkan aspel kualitas pelayanan yang meliputi lima dimensi maka dapat dibuat ringkasan mean dari masingmasing dimensi sebagai berikut.

Tabel 12. Rata-Rata Tanggapan Responden Atas Kualitas Pelayanan PERUMDA Tirta Muaro Unit Teluk Singkawang Kecamatan Sumay Kabupaten Tebo

\begin{tabular}{clc}
\hline No. & Dimensi Kualitas Pelayanan & Mean \\
\hline 1. & Tengible & 3,51 \\
2. & Responsiveness & 2,82 \\
3. & Reliability & 3,99 \\
4. & Assurance & 3,77 \\
5. & Emphaty & 3,66 \\
\hline \multicolumn{2}{r}{ Rata-Rata } \\
\hline
\end{tabular}

Berdasarkan rata-rata tanggapan responden terhadap kualitas pelayanan, maka diketahui kualitas pelayanan yang ada pada PERUMDA Tirta Muaro Unit Teluk Singkawang Kecamatan Sumay Kabupaten Tebo sebesar 3,54 dimana skor ini mendekati skor 4 yang dapat diinterprestasikan kualitas pelayanan tergolong cukup baik. Dari kelima dimensi pelayanan diketahui bahwa reliability memiliki rata-rata tertinggi dan responsiveness memiliki rata-rata terendah.

\subsection{Uji Statistik Data}

Pada penelitian ini dilakukan uji validitas, uji reliabililitas, uji normalitas, uji multikolonieritas, uji heterokedastisitas, uji secara simultan (uji F) dan uji secara parsial (uji t).

\section{Uji Validitas}

Berikut adalah hasil uji validitas dpada masing-masing variabel penelitian.

Tabel 13. Hasil Uji Validitas

\begin{tabular}{clrrl}
\hline No. & \multicolumn{1}{c}{ Variabel } & Rhitung & Rtabel & Hasil \\
\hline 1. & Variabel X.1 (Tangible) & 1,000 & 0,22 & Valid \\
2. & Variabel X.2 (Responsiveness) & 0,584 & 0,22 & Valid \\
3. & Variabel X.3 (Reliability) & 0,252 & 0,22 & Valid \\
4. & Variabel X.4 (Assurance) & 0,623 & 0,22 & Valid \\
5. & Variabel X.5 (Empathy) & 0,624 & 0,22 & Valid \\
6. & Variabel Y (Kepuasan) & 0,297 & 0,22 & Valid \\
\hline
\end{tabular}

Hasil perhitungan validitas menunjukkan item pertanyaan untuk variabel tangible, responsiveness, reliability, assurance, empathy dan kepuasan dinyatakan masing-masing instrumen mempunyai nilai koefisien korelasi ( $\mathrm{r}$ hitung) yang lebih besar dari koefisien kritis ( $\mathrm{r}$ tabel). Hal ini menunjuka bahwa masing-masing item adalah valid /sahih.

\section{Uji Reliabilitas}

Berdasarkan hasil perihtungan pada Lampiran didapatkan hasil koefisien alpha sebagai berikut.

\begin{tabular}{ll}
\multicolumn{2}{c}{ Tabel 14. Uji Reliabilitas } \\
\hline Cronbach's Alpha & N of Items \\
\hline, 642 & 6 \\
\hline
\end{tabular}

Koefesien alfa dinyatakan reliablel karena lebih besar dari 0,6. Dengan demikian pertanyaan kuesioner pada masing-masing indikator variabel penelitian dinyatakan reliable dan selanjutnya dapat digunakan dalam penelitian ini.

\section{Uji Normalitas}

Uji normalitas bertujuan untuk menguji apakah dalam model regresi, variabel terikat dan variabel bebas keduanya mempunyai distribusi normal atau tidak. Model regresi yang baik memiliki distribusi data normal atau mendekati normal. Untuk mengetahui hal tersebut dapat menggunakan uji komogorov smirnov (K-S). Apabila nilai probabilitas $>$ nilai $\alpha$ $=0,05$, maka data terdistribusi secara normal dan apabila nilai probabilitas $<$ nilai $\alpha=0,05$, maka data tidak terdistribusi secara normal. Beriktu disajikan tabel yang merupakan hasil output uji normalitas data.

Berdasarkan output uji normalitas yang terdapat di atas bahwa nilai Upper Bound Monter Carlo Sig. sebesar 0,011 lebih besar dari 0,05, dengan demikian dapat disimpulan bahwa data yang akan dianalisis terdistribusi normal.

\section{Uji Multikolonieritas}

Uji Multikolonieritas adalah korelasi tinggi yang terjadi antara variabel bebas satu dengan variabel bebas lainnya. Uji multikolonieritas bertujuan untuk menguji apakah model regresi ditemukan adanya korelasi antar variabel bebas (independen). Model regresi yang baik seharusnya tidak terjadi korelasi diantara variabel independent. Nilai tolerance $<0,10$ dan nilai VIF >10 maka dikatan bahwa ada multikolonieritas antar variabel dalam model regresi. Berikut disajikan tabel yang merupakan hasil output uji mulitkolonieritas.

Tabel 16. Hasil Uji Multikolonieritas

\begin{tabular}{|c|c|c|c|}
\hline \multirow[b]{2}{*}{ Model } & & \multicolumn{2}{|c|}{ Collinearity Statistics } \\
\hline & & Tolerance & VIF \\
\hline 1 & (Constant) & & \\
\hline & Score_X1 & 425 & 2,355 \\
\hline & Score_X2 & ,517 & 1,933 \\
\hline & Score_X3 & ,711 & 1,407 \\
\hline & Score_X4 & ,409 & 2,443 \\
\hline & Score_X5 & ,439 & 2,278 \\
\hline
\end{tabular}

Berdasarkan output uji multikolonieritas di atas bahwa hasil perhitungan nilai tolerance dari masing-masing dimensi independent lebih besar 0,10 yang berarti tidak ada korelasi antar variabel independent. Hasil perhitungan VIF dari masing-masing dimensi independent lebih kecil dari 10. Jadi dapat disimpulkan bahwa tidak ada multikolonieritas antar variabel independent dalam model regresi.

\section{Uji Heterokedastisitas}

Uji Heterokedastisitas bertujuan menguji apakah dalam model regresi terjadi ketidaksamaan varience dari residual satu 
pengamatan ke pengamatan yang lain. Uji heterokedastisitas pada data ini dilakukan dengan cara melihat grafik scatter plot antara nilai prediksi variabel terikat (ZPRED) dengan residual (SRESID). Berikut hasil uji heterokedastisitas.

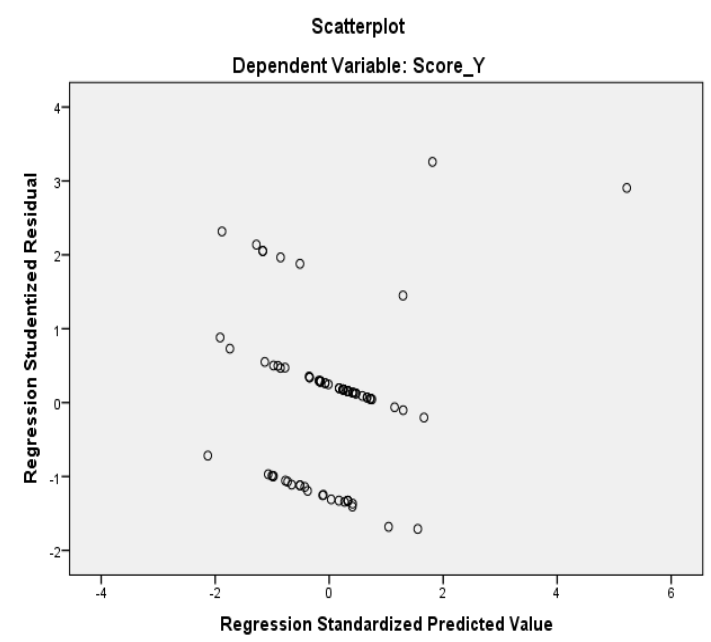

Gambar 1. Scatter Plot Uji Heterokedastisitas

Dari gambar scatter plot di atas menunjukkan bahwa tidak ada pola yang jelas, serta titik-titik menyebut di atas dan di bawah adalah angka nol pada sumbu Y, maka tidak ada heterokedastisitas.

\section{Pengujian Secara Simultan (Uji F)}

Pengujian hipotesis ini dimaksudkan untuk mengetahui sebuah tafsiran parameter secara bersama-sama, yang artinya seberapa besar pengaruh dari dimensi tangibless, responsiveness, reliability, assurance dan empathy terhadap dimensi kepuasan secara bersama.

Tabel 17. Hasil Uji F

\begin{tabular}{llr|r|r|r|r}
\hline \multirow{2}{*}{ Model } & $\begin{array}{c}\text { Sum of } \\
\text { Squares }\end{array}$ & \multicolumn{1}{c}{ df } & $\begin{array}{c}\text { Mean } \\
\text { Square }\end{array}$ & \multicolumn{1}{c}{ F } & Sig. \\
\hline \multirow{2}{*}{1} & Regression & 2,485 & 5 &, 497 & 1,069 &, $385^{\text {b }}$ \\
\cline { 2 - 7 } & Residual & 34,403 & 74 &, 465 & & \\
\cline { 2 - 8 } & Total & 36,888 & 79 & & & \\
\hline
\end{tabular}

$\mathrm{H}_{0}: \mathrm{b}_{1,2,3,4,5}=0$, artinya dimensi tangibles, responsiveness, reliability, assurance dan empathy secara bersama-sama tidak berpengaruh terhadap kepuasan.

$\mathrm{H}_{0}: \mathrm{b}_{1,2,3,4,5}>0$, artinya dimensi tangibles, responsiveness, reliability, assurance dan empathy secara bersama-sama berpengaruh terhadap kepuasan.

Berdasarkan grafik di atas menunjukkan bahwa Fhitung $=1,069$ dengan tingkat kesalahan 0,385 (0,0385 > 0,050, maka hipotesis ini menolak Ho dan menerima Ha, artinya bahwa secara keseluruhan dimensi Tangibles, responsiveness, reliability, assurance dan empathy secara bersama-sama berpengaruh terhadap kepuasan pelanggan PERUMDA Tirta Muaro Unit Teluk Singkawang Kecamatan Sumay Kabupaten Tebo.

\section{Uji Parsial (Uji t)}

Uji t ini juga dapat disebut uji parsial, pengujian ii bertujuan untuk menguji signifikansi hasil uji regresi linier berganda. Pembutkian hipotesis ini yaitu memperhatikan nilai $\mathrm{t}$ hitung dan signifikan. Untuk uji t didapat hasil sebagai berikut.

Tabel 18. Hasil Uji t

\begin{tabular}{|c|c|c|c|}
\hline \multicolumn{2}{|c|}{ Model } & $\mathrm{T}$ & Sig. \\
\hline \multirow[t]{6}{*}{1} & (Constant) & 5,599 &, 000 \\
\hline & Score_X1 (Tengible) &,- 175 & 862 \\
\hline & Score_X2 (Responsiveness) &, 729 & ,468 \\
\hline & Score_X3 (Reliability) & ,449 & 655 \\
\hline & Score_X4 (Assurance) &,- 560 &, 577 \\
\hline & Score_X5 (Empathy) & $-1,327$ & ,188 \\
\hline
\end{tabular}

Berdasarkan hasil nilai $t_{\text {hitung }}$ dimensi tangibles sebesar $-0,175$ dengan tingkat signikan $\mathrm{t}$ sebesar 0,000 lebih kecil dari $0,05(0,000<0,05)$ maka hipotesis penelitian ini menolah Ho dan menerima Ha. Hipotesis yang menyatakan menerima menunjukkan bahwa dimensi tangibles secara partial memiliki pengaruh yang signifikan terhadap kepuasan pelanggan PERUMDA Tirta Muaro Unit Teluk Singkawang Kecamatan Sumay Kabupaten Tebo.

Berdasarkan hasil nilai thitung dimensi responsiveness sebesar 0,729 dengan tingkat signikan t sebesar 0,468 lebih besar dari $0,05(0,468>0,05)$ maka hipotesis penelitian ini menerima Ho dan menolak Ha. Hipotesis yang menyatakan menerima menunjukkan bahwa dimensi responsiveness secara partial tidak memiliki pengaruh yang signifikan terhadap kepuasan pelanggan PERUMDA Tirta Muaro Unit Teluk Singkawang Kecamatan Sumay Kabupaten Tebo.

Berdasarkan hasil nilai $t_{\text {hitung }}$ dimensi reliability sebesar 0,449 dengan tingkat signikan t sebesar 0,655 lebih besar dari $0,05(0,655>0,05)$ maka hipotesis penelitian ini menerima Ho dan menolak Ha. Hipotesis yang menyatakan menerima menunjukkan bahwa dimensi realibility secara partial tidak memiliki pengaruh yang signifikan terhadap kepuasan pelanggan PERUMDA Tirta Muaro Unit Teluk Singkawang Kecamatan Sumay Kabupaten Tebo.

Berdasarkan hasil nilai thitung dimensi assurance sebesar $-0,560$ dengan tingkat signikan $\mathrm{t}$ sebesar 0,577 lebih besar dari $0,05(0,577>0,05)$ maka hipotesis penelitian ini menerima Ho dan menolak Ha. Hipotesis yang menyatakan menerima menunjukkan bahwa dimensi assurance secara partial tidak memiliki pengaruh yang signifikan terhadap kepuasan pelanggan PERUMDA Tirta Muaro Unit Teluk Singkawang Kecamatan Sumay Kabupaten Tebo.

Berdasarkan hasil nilai thitung dimensi empathy sebesar 1,327 dengan tingkat signikan t sebesar 0,188 lebih besar dari $0,05(0,188>0,05)$ maka hipotesis penelitian ini menerima Ho dan menolak Ha. Hipotesis yang menyatakan menerima menunjukkan bahwa dimensi realibility secara partial tidak memiliki pengaruh yang signifikan terhadap kepuasan pelanggan PERUMDA Tirta Muaro Unit Teluk Singkawang Kecamatan Sumay Kabupaten Tebo.

\section{Kesimpulan}

Berdasarkan hasil penelitian yang telah dilakukan, maka ditarik kesimpulan bahwa kepuasan pelanggan terhadap pelayanan air bersih PERUMDA Tirta Muaro Unit Teluk Singkawang dianalisis berdasarkan 5 (lima) dimensi kualitas pelayanan yaitu tangible, reliability, responsiveness, assurance dan empathy dan regresi linear berganda diperoleh bahwa 
kepuasan pelanggan terhadap pelayanan air bersih PERUMDA Tirta Muaro Unit Teluk Singkawang dinyatakan puas berdasarkan hasil kepuasan pelanggan terhadap kualitas pelayanan air bersih PERUMDA Tirta Muaro Unit Teluk Singkawang.

\section{Daftar Pustaka}

Anandar. (2015). Pengaruh Kualitas Pelayanan Jasa PDAM Tirta Kecana Kota Samarinda Terhadap Kepuasan Pelanggan Di Wilayah Kelurahan Sungai Pinang Dalam Kecamatan Sungai Pinang, Journal Administrasi Negara 3 (4) 2015: 1103-1114

Anggreini, Nunik. (2016). Pengaruh Kualitas Pelayanan Air Bersih Terhadap Kepuasan Masyarakat Pada PDAM di Kecamatan Sesayap Kabupaten Tana Tidung. Tesis. Program Pascasarjana Universitas Terbuka Jakarta

Arikunto, Suharsimi. (2006). Prosedur Penelitian Suatu Pendekatan Praktik. Jakarta: Rineka Cipta.

Badan Pusat Statistik. (2020). Kabupaten Tebo Dalam Angka 2021. Jambi: Badan Pusat Statistik

Batubara, A. W., Ginting, P., dan Nurbaity, A. (2014). Pengaruh Kualitas Pelayanan Terhadap Kepuasan dan Word Of Mouth Mahasiswa Program Studi Diploma III Administrasi Perpajakan Fisip USU. Journal Manajemen \& Bisnis, Vol. 14,No. 02

Zeithaml, V.A., M.J. Bitner, D.D. Gremler. 2013. Services Marketing: Integrating Customer Focus Across the Firm6thed. Mc.Graw-Hill. Boston.

Djaali, A. (2008). Skala Likert. Yogyakarta: Andi Offset.

Fauziah. (2013). Kualitas Pelayanan Penjualan Tiket pada PT. Bonanza Pekanbaru Holiday Tour \& Travel. Jurnal Universitas Riau

Ghozali, Imam. (2005). Aplikasi Analisis Multivariate dengan Program SPSS. Edisi 3. Semarang: Badan Penerbit Universitas Diponegoro

Isnawati, Dian \& Suhariadi Fendy. (2013). Hubungan antara Dukungan Sosial dengan Penyesuaian Diri Masa Persiapan Pensiun pada Karyawan PT Pupuk Kaltim. Jurnal Psikologi Industri dan Organisasi. Vol. 1, Februari 2013, Hal. 1-6. Departemen Psikologi Industri dan Organisasi Fakultas Psikologi Universitas Airlangga.

Kotler, P., dan Keller (2009) Manajemen Pemasaran, Edisi Ketiga Belas Jilid I. Jakarta: Penerbit Erlangga

Rafiq, Muhammad. (2017). Penilaian Kinerja Perusahaan Daerah Air Minum Tirta Jeneberang Kabupaten Gowa. Skripsi. Universitas Hasanuddin.

Rangkuti, F. (2006). Measuring Customer Satisfaction: Gaining Customer Relationship Strategy Teknik Mengukur dan Meningkatkan Kepuasan Pelanggan. Jakarta: Gramedia Pustaka Utama

Ratminto \& Atik Septi Winarsih. (2005). Manajemen Pelayanan. Yogyakarta: Pustaka Pelajar.

Sutrisman. (2014). Analisis Pengaruh Kualitas Pelayanan, Kualitas Kinerja Pegawai dan Kualitas Barang Terhadap Kepuasan Pelanggan Kelompok Rumah Tangga PDAM Kabupaten Seruyan, Jurnal Administrasi Publik dan Birokrasi Vol. 1 No. 3, 2014

Ulfa, Nurmalia. (2019). Identifikasi Permasalahan Sistem $\backslash$ Penyediaan Air Minum Di Kabupaten Gunung Kidul, DIY. Skripsi. Universitas Gajah Mada
Peraturan Menteri Kesehatan Nomor 492 Tahun 2010 Tentang Persyaratan Kualitas Air Minum

Peraturan Menteri Pekerjaan Umum Republik Indonesia Nomor. 18/PRT/M/2012 Tentang Pedoman Pembinaan Penyelenggaraan Pengembangan Sistem Penyediaan Air Minum

Peraturan Menteri Pekerjaan Umum Republik Indonesia Nomor 13/PRT/M/2013 Tentang Kebijakan dan Strategi Nasional Pengembangan Sistem Penyediaan Air Minum

Peraturan Pemerintah Republik Indonesia. Nomor 122 Tahun 2015. Tentang Sistem Penyediaan Air Minum

Puspita, R. N. (2012). Perbedaan Kepuasan Pelanggan Indomaret dan Alfamart. Journal Of Social and Industrial Psychology, Vol. 1 No. 1

Rafiq, Muhammad. (2017). Penilaian Kinerja Perusahaan Daerah Air Minum Tirta Jeneberang Kabupaten Gowa. Skripsi. Universitas Hasanuddin.

Rangkuti, F. (2006). Measuring Customer Satisfaction: Gaining Customer Relationship Strategy Teknik Mengukur dan Meningkatkan Kepuasan Pelanggan. Jakarta: Gramedia Pustaka Utama

Ratminto \& Atik Septi Winarsih. (2005). Manajemen Pelayanan. Yogyakarta: Pustaka Pelajar.

Sugiyono. (2012). Metode Penelitian Kuantitatif, Kualitatif dan $R \& D$. Bandung: Afabeta

Suliyanto. (2006). Metode Riset Bisnis. Yogyakarta: Andi.

Sutrisman. (2014). Analisis Pengaruh Kualitas Pelayanan, Kualitas Kinerja Pegawai dan Kualitas Barang Terhadap Kepuasan Pelanggan Kelompok Rumah Tangga PDAM Kabupaten Seruyan, Jurnal Administrasi Publik dan Birokrasi Vol. 1 No. 3, 2014

Ulfa, Nurmalia. (2019). Identifikasi Permasalahan Sistem Penyediaan Air Minum Di Kabupaten Gunung Kidul, DIY. Skripsi. Universitas Gajah Mada

Zeithaml, V.A., M.J. Bitner, D.D. Gremler. 2013. Services Marketing: Integrating Customer Focus Across the Firm6thed. Mc.Graw-Hill. Boston. 